\title{
sciendo
}

\section{THE EFFECTS OF DEOXYNIVALENOL (DON) ON THE GUT MICROBIOTA, MORPHOLOGY AND IMMUNE SYSTEM OF CHICKEN - A REVIEW}

\author{
Harry A. Aguzey, Zhenhua Gao*, Wu Haohao, Cheng Guilan, Wu Zhengmin, Chen Junhong \\ Department of Animal Science, College of Agriculture, \\ Guangdong Ocean University, Zhanjiang, Guangdong 524088, P.R China \\ •Corresponding author: xmsgzhh@126.com
}

\begin{abstract}
Feed contamination is a major cause of diseases outbreak in the poultry industry. There is a direct relationship between feeding, the intestinal microbiota and how the immune system responds to disease infestation. Cereals which form the bulk of poultry feed are mostly contaminated by mycotoxins of Fusarium origin. Adequate knowledge of mycotoxins and their effects on animals is necessary. Deoxynivalenol (DON) is a major contaminant of poultry feed. DON has the ability to bind with a large number of eukaryotic ribosomal subunits because of the presence of an epoxide group and these disrupt the activity of peptidyl transferase and the elongation or shortening of peptide chains. Deoxynivalenol has varying effect ranging from acute, overt diseases with high morbidity and death to chronic disease, decreased resistance to pathogens and reduced animal productivity. Deoxynivalenol also impairs the intestinal morphology, nutrient absorption, barrier function, and the innate immune response in chickens. This review highlights the impacts of deoxynivalenol on the immune system, intestinal microbiota composition and the morphology of chicken.
\end{abstract}

Key words: deoxynivalenol, microbiota composition, immune system, intestinal morphology, mycotoxins

The purpose of every poultry industry is to ensure high productivity and improve upon quality at a low cost. This, coupled with increase in the human population and its corresponding demand for poultry meat and products, has necessitated that there should be constant, efficient and goal-oriented healthcare to prevent the development of diseases leading to loss in the industry. One major cause of diseases in the poultry industry is contamination of feed. There is a direct relationship between feeding, the intestinal microbiota and how the immune system responds to disease infestation (Wise and Siragusa, 2007; Kohl and Dearing, 2012; Oakley et al., 2013). One major mode of contamination of plant products is by mycotoxins of Fusarium origin (Pinton et al., 2008). These plant products are mostly used in the production of food 
and feed (Martins, 2018; Reddy et al., 2018), of which cereals account for a large part of these plants products in the preparation of human and animal diets (StuperSzablewska et al., 2016). To ensure that feed is not contaminated, knowledge about mycotoxins and their effect on animals is very important (Gajęcka et al., 2017; Liew and Mohd-Redzwan, 2018). Among the mycotoxins, the commonest are deoxynivalenol (DON), zearalenone (ZEN) and its metabolites, $\alpha$-zearalenol $(\alpha-Z E L)$ and $\beta$-zearalenol ( $\beta$-ZEL), with $58 \%$ and $41,157 \mu \mathrm{g} / \mathrm{kg}$, for deoxynivalenol, and $46 \%$ and $3049 \mu \mathrm{g} / \mathrm{kg}$ for zearalenone, respectively (Schatzmayr and Streit, 2013; Lee and Ryu, 2017). The mycotoxin deoxynivalenol is a polar organic compound with formula 12,13-epoxy-3 $\alpha, 7 \alpha, 15$-trihydroxy-trichothec-9-en-8-one (Maresca and Fantini, 2010), having a ketone group on the $C 8$ which is a characteristic feature of type $B$ trichothecenes. The number and location of hydroxyl groups and acetyl esters can also determine the compound's relative toxicity inside cells (Pestka, 2004). DON has the ability to bind with a large number of eukaryotic ribosomal subunits because of the presence of an epoxide group (Pestka, 2010) and this disrupts the activity of peptidyl transferase and the elongation or shortening of peptide chains. Deoxynivalenol (DON) is a mycotoxin produced by Fusarium species. It is found mostly in cereals such as corn, barley, wheat, rye and sometimes in rice and sorghum and it is considered as one of the most important trichothecenes. Trichothecenes are the main and chemically most diverse group of the three major classes of Fusarium mycotoxins (Summerell and Leslie, 2011). They represent a large family of chemically related toxins produced by fungi in taxonomically unrelated genera, such as Fusarium, Myrothecium, and Stachybotrys and present a potential threat to animal health throughout the world ( $\mathrm{Li}$ et al., 2011). They are classified into four groups (A, B, C and D) based on their substitution pattern, all containing a common 12,13-epoxytrichothecene group which is responsible for their cytotoxicity and a 9,10 double bond with various side chain substitutions. Deoxynivalenol (DON) and its 3-acetyl and 15-acetyl derivatives is a type B and contains a keto (carbonyl) function at $\mathrm{C}-8$ and includes fusarenon-X and nivalenol (NIV). The occurrence of deoxynivalenol is associated primarily with Fusarium graminearum (Gibberella zeae) and F. culmorum (Alassane-Kpembi et al., 2015). Mycotoxins of Fusarium origin often contaminate cereal grains which constitute the bulk of feed for poultry. Several researchers have investigated the effects of DON mycotoxin on the functions of the immune system ranging from immunosuppression to immunostimulation and reported that these impact is dependent on the concentration, duration and time of exposure (Bondy and Pestka, 2000; Pinton et al., 2010; Becker et al., 2011). Pestka (2003) reported that concentrations of DON (less than $5 \mathrm{mg} / \mathrm{kg}$ feed) seem to be responsible for stimulation of immunity and high concentrations seem to suppress the immune responses. Desjardins (2006) also reported that chronic DON intoxication at high concentrations lead to injuries of rapidly and actively dividing cells of immune organs and mucosa of the gastrointestinal tract. The toxin binds to the $60 \mathrm{~S}$ subunit of ribosomes thereby inhibiting the synthesis of protein. This induces a stress response and mitogen activated protein kinases (MAPKs) are activated, due to ribosomal conformational changes affecting the peptidyl transferase activity of ribosomes. An important activity of MAPKs is their effect on transcription factors. Higher expression 
of nuclear factor $\kappa \mathrm{B}(\mathrm{NF}-\mathrm{\kappa B})$ induces the expression of pro-inflammatory cytokines affecting immune reactions in animals (Rocha et al., 2005). The important role being played by the intestinal microbiota of broiler chickens in ensuring optimum growth performance and good health of birds cannot be underestimated (Bjerrum et al., 2006). The influence of these microbiota are particularly important at the young stage since it would still be in the process of development (Gong et al., 2015). The interaction of intestinal growth, digestive functions, and diet is critical during the post-hatching period when birds switch to solid feed nutrition. Among the numerous functions of the microflora populations in the digestive tract of chicken is the promotion of immune system development and function, nutrition and function, metabolism and pathogen exclusion (Guarner and Malagelada, 2003; Noverr and Huffnagle, 2004; Macpherson and Harris, 2004; Backhed et al., 2005; Guarner, 2006; Round and Mazmanian, 2009). Several researches have reported that the balance and regulation of helper T cells (Th1, Th2, Th17), in helping protect the host from the invasion of enteric pathogens is greatly influenced by intestinal microbiota (Ivanov et al., 2008). Ley et al. (2006) also found that germ-free chicken lacking microbiota have few plasma cells, decreased IgA levels, and under-developed Peyer's patches in the small intestine, resulting in increased susceptibility to enteric pathogens. The gut of birds is colonized by environmental microbes immediately after hatching. Several factors such as nutrient composition of diet, age, medication and stress account for the composition of the gut microbiota (De La Cochtiere et al., 2008; Claesson and O'Toole, 2010; Claesson et al., 2011). For the complete maintenance of animal health, there must be homeostasis. In the absence of homeostasis, the animals are predisposed to several diseases. The gut microbiota composition is readily changeable (Jia et al., 2008); depending on the environmental condition prevalent and the nutrient composition of feed. Although some are beneficial to the growth of the animal, others are harmful. It is therefore imperative that the safety of the total environment and the nutrient composition and state of the feed must be greatly taken into consideration to ensure optimum performance (Claesson and O'Toole, 2010). The aim of this review is to assess the impact of deoxynivalenol (DON) on the gut microbiota, morphology and subsequently its effect on the immune system of chicken.

\section{Deoxynivalenol (DON) in poultry feed}

Deoxynivalenol (DON), also called vomitoxin, is a major contaminant of feedstuffs worldwide, produced by Fusarium graminearum (Gibberella zeae) and F. culmorum (Romers Lab Guide, 2000). It is found in cereal grains (wheat, maize, barley, oat and rye and less often in rice and sorghum) which form the bulk of feed for livestock. Fusarium graminearum and F. culmorum can survive in the leaves of the cold season and be a source of infection for the new crop. Cool temperatures and high humidity are the environmental conditions that favor the fungal development in the field (Dersjant-Li et al., 2003; Richard, 2007). If grains are not properly stored after harvesting, and are exposed to high moisture conditions, it gives rise to the fungal infestation. After infection of grains, F. graminearum infestation results in the disease known as ear rot in corn or head blight in wheat and barley (Richard, 2007). One sign associated with deoxynivalenol contamination is when corn kernels ripen prema- 
turely, unevenly and have a blanched appearance. The natural occurrence of DON in grains used for poultry is normally between 0 and $5 \mathrm{mg} / \mathrm{kg}$, although concentrations can be higher (Dersjant-Li, 2003). However, improved storage conditions $(<14 \%$ moisture) will minimize further elaboration of DON. Fusarium mycotoxins have the property of exerting both acute and chronic toxic effects and this characteristic makes them a major cause of broad varieties of toxic effects in animals. These fungal compounds have varying effect ranging from acute, overt diseases with high morbidity and death to chronic disease, decreased resistance to pathogens and reduced animal productivity. Kanora and Maes (2009) reported that even when low levels of toxins are ingested, the metabolic, physiological and immunological properties of the animal are compromised, with symptoms associated with mycotoxicosis being evident. Since it is a common practice to use multiple grain sources in animal diets, the risk of exposure to several mycotoxins increases with diet complexity (Grenier and Applegate, 2013). The hemical structure of DON is shown in Figure 1.

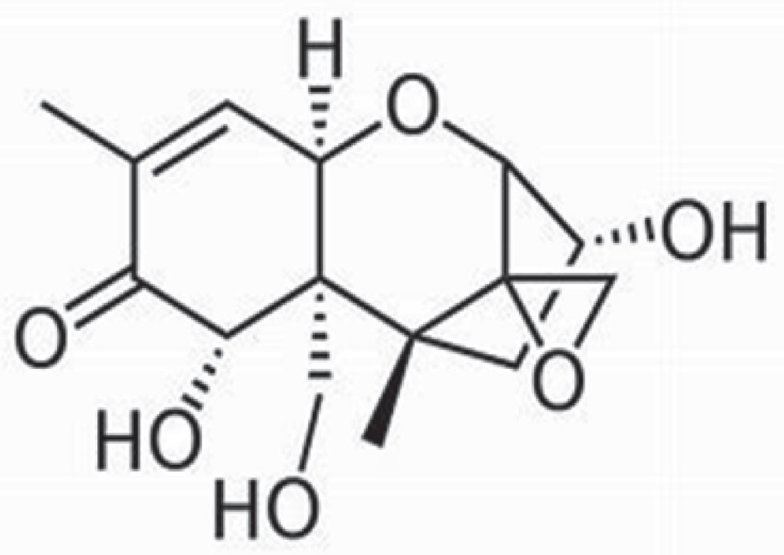

Figure 1. The chemical structure of deoxynivalenol

\section{The gut microbiota, morphology and deoxynivalenol (DON)}

The gut microbiota is very important in ensuring the health of the animal is not compromised. Among the numerous roles it plays are the modulation of the gut epithelial barrier, responding to inflammations, synthesis of vitamins, dietary fiber fermentation and providing protection against pathogen colonization (Maslowski and Mackay, 2011; Kogut and Arsenault, 2016). Bacteroidaceae, Ruminococcaceae, Lachnospiraceae and Clostridiaceae are the dominant bacterial taxa in chicken and they are highest in the ceca (Oakley et al., 2014). Moreover, the longer retention time of digesta in the ceca allows for a more complete microbial breakdown of complex fiber and enhances short-chain fatty acid (SCFA) production compared to the other gut sites (Oakley et al., 2014). Cereals form the bulk of poultry feed but there is the likelihood of it being contaminated by the Fusarium toxin deoxynivalenol (DON) 
which is very harmful for animal health (Escrivá et al., 2015), and causes substantial economic losses in poultry production (Awad et al., 2013). Andretta et al. (2011) reported that chickens are sensitive to moderate DON levels that compromise feed intake, growth performance and functioning of the immune system. The current guidance value of The European Union's standard for DON in poultry feed is $5 \mathrm{mg}$ DON/kg feed (12\% moisture) (2006/576/EC, 2006). When consumed, DON impairs the intestinal morphology, nutrient absorption, barrier function, and the innate immune response in chickens (Awad et al., 2011 b; Osselaere et al., 2013; Lucke et al., 2017 b). The gastrointestinal mucosa among other functions serves as a dynamic barrier, regulating uptake of nutrients and water, while excluding potential pathogens and toxicants (Eriksen and Pettersson, 2004). These functions are impaired upon ingestion of contaminated feed (Desjardins, 2006). Lipopolysaccharides (LPS) are immune-stimulatory compounds which are released by the gut microbiota (Saadia et al., 1990; Ge et al., 2000; Ghareeb et al., 2016; Lucke et al., 2017 a). These compounds are part of the outer membrane of Gram negative bacteria and may suppress growth performance in poultry by diverting energy for an elevated immune response (Ghareeb et al., 2016). Problems associated with LPS include damage to the gut mucosal tissue (Wu et al., 2013), modifying mucus secretion and composition in vitro (Dohrman et al., 1998; Smirnova et al., 2003; Cornick et al., 2015; Zhang et al., 2017). Moreover, evidence suggests that LPS can interfere with the response to other xenobiotic agents. Trichothecenes are small, amphipathic molecules that can move passively across cell membranes. They are easily absorbed via the integumentary and gastrointestinal systems, allowing for a rapid effect of ingested trichothecenes on rapidly proliferating tissues (Pinton and Oswald, 2014). Trichothecenes are toxic to animals and its exposure has been linked to reproductive disorders in domestic animals (Cortinovis et al., 2013). Damage to the gut barrier in duodenum and jejunum may modify intestinal nutrient flows with consequences for the microbial composition and metabolism in the ceca. Robert et al. (2017) reported that DON and other mycotoxins target the mucus and microbiota composition of their hosts, causing damage to the tissue of the gut, shortening the height of the villi, stop differentiation of gut cells and destabilize the composition of the gut (Suzuki and Iwahashi, 2015). The gastrointestinal tract (GIT) exhibits several characteristics such as chemical, physical, immunological and microbiological, all geared towards ensuring that its function of serving as a barrier against toxins and contaminants is not compromised (Bouhet et al., 2004). The villi, the minute membranes lining the mucous membrane of the small intestine serve as a site for the absorption of nutrients. Upon exposure of the villi to DON contaminated diets, there is atrophy of the villi in broilers (Awad et al., 2004, 2006, 2011). The structures of duodenal and jejunal mucosa villi are also affected and they become thinner and shorter on exposure to DON (Awad et al., 2011). This adversely affects the digestive and absorptive functions of the intestines. To maintain and ensure proper mucosal integrity, the gut barrier function of the epithelial cell layer needs to be in the best of shape. The integrity is mostly provided by the tight and adherence junctions of the epithelial cells which are known to be affected by fungal toxins (Bouhet et al., 2004). There are negative effects when the immune organs, liver and the small intestines are exposed to DON (Feinberg 
and McLaughlin, 1989). A research conducted on Peking ducks showed that feeding with an increasing proportion of DON contaminated wheat $(6-7 \mathrm{mg} \mathrm{DON} / \mathrm{kg}$ and 0.05-0.06 $\mathrm{mg} \mathrm{ZEN} / \mathrm{kg}$ ) led to a decrease of the relative weight of the bursa of Fabricius (Dänicke et al., 2004), which in turn may decrease the production of antibodies. It was also discovered that in ducks, higher weights were recorded for the heart, liver and pancreas after feeding of DON (Cheng et al., 2004), while in broilers, gizzard, heart and bursa of Fabricius were having a higher weight (Kubena et al., 1985; Kubena et al., 1997). DON also had an irritant effect on the gizzard mucosa and a decrease in the weight of the small intestine of laying hens when fed a concentration of 3.4 and $9.9 \mathrm{mg} / \mathrm{kg}$ Fusarium mycotoxin (Dänicke et al., 2002). DON causes a disruption in the synthesis of protein thereby influencing the rate of passage across cell membrane (Lun et al., 1989; Waśkiewicz et al., 2014), affects the role of enzymes in metabolism in the cytoplasm, changes in affinity for an active binding site (Pinton and Oswald, 2014). These properties enable DON to influence specific tissues and organs. For the mycotoxin to take effect, it has to be released from the food matrix and absorbed from the intestines (Pinton et al., 2012) into the bloodstream, whereby it can affect the structural properties of intestinal mucosa and animal productivity.

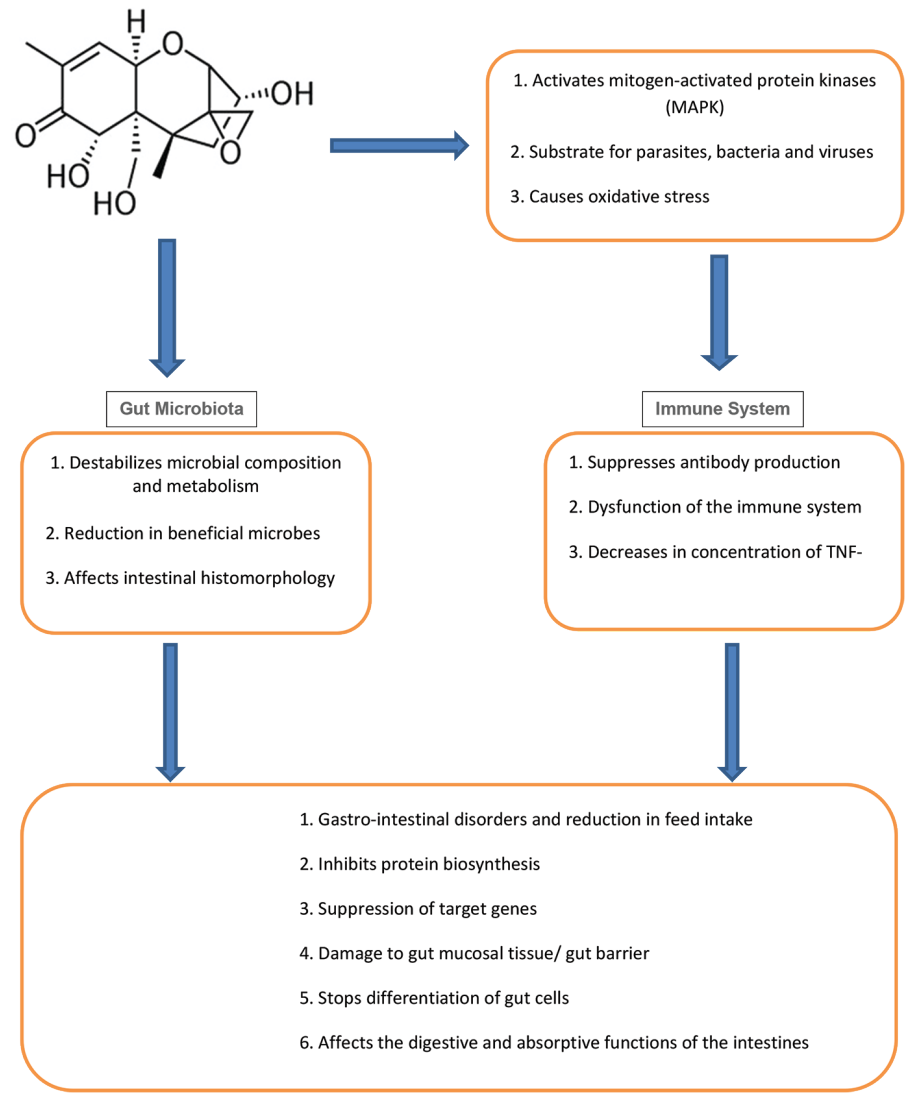

Figure 2. Effects of DON on the gut microbiota and immune system of chicken 


\section{The immune system and deoxynivalenol (DON)}

The immune system is composed of interacting cells, tissues and proteins that form two distinct arms: the innate and adaptive immune responses. The innate immune system is the first line of defense and is rapid and non-specific but lacks memory of pathogens; therefore, it does not need prior experience of a pathogen to mount an attack, but subsequent challenges by the same pathogen result in a similar response to that of the first exposure (Lun et al., 1986). Adaptive immunity, however, is very slow to reach protective levels upon an initial exposure to a pathogen, but class switching occurs and the memory B cells generated are stored, which permits a rapid and specific defense against subsequent exposures to the same pathogen. At hatching, birds are quite vulnerable to environmental pathogens, as the immune system had not matured. At this early stage of life there is a strong reliance on maternal antibodies and innate immune function (Levy, 2007) whilst the adaptive immune system gradually develops in response to microflora colonization (Klasing and Leshchinsky, 1999; Klasing, 2004). The immune system serves among other functions to recognize foreign substances and organisms (antigens) that are able to enter the body and thereby initiate and manage appropriate physiological responses to neutralize and eliminate these organisms and substances. In a bid to achieve this goal, several mechanisms come into play, including inactivation of biological agents, lysis (rupture) of foreign cells, agglutination (clumping) or precipitation of molecules or cells, or phagocytosis (engulfing and inactivating) of foreign agents. There is varying literature regarding the impact of feeding DON on the health and performance traits in poultry. This notwithstanding, it is established that there is a dysfunction of the immune system of birds when exposed to DON, predisposing the birds to infectious diseases (Lun et al., 1986; Oswald et al., 2005). Ghareeb et al. (2012) and Dänicke et al. (2002) reported that birds that were exposed to DON had suppressed antibody response to infectious bronchitis vaccine (IBV) and Newcastle disease virus. DON decreased the concentration of tumor necrosis factor alpha (TNF- $\alpha$ ) in plasma of broiler chickens (Awad et al., 2012). TNF- $\alpha$ is an important cytokine involved in systemic inflammation and stimulates the acute phase reaction. DON, therefore, can interfere with production of TNF- $\alpha$ from macrophages. DON also has adverse effect on the intestinal histomorphology, electrophysiology, absorption and barrier function in chickens (Awad et al., 2004, 2006 a, 2006 b; Girgis et al., 2010). The negative effects of DON on the health and growth performance of broiler chickens have been documented (Yunus et al., 2012; Antonissen et al., 2015). Because of its potential of serving as a protein inhibitor, it is able to initiate apoptosis by activating mitogenactivated protein kinases. This leads to a variety of lesions and symptoms including growth retardation, feed refusal and gastrointestinal disorders (Awad et al., 2006; Awad et al., 2012). Mycotoxins undergo the same processes as drugs (absorption, distribution, metabolisation and excretion). Mycotoxins sometimes act as substrates, inhibitors or inducers to these metabolizing enzymes. Several experiments done in vivo and in vitro showed absorption of DON mostly occurs from the stomach to the proximal jejunum, leading to inhibition of protein synthesis and suppression of various target genes, including amino acid transporters (Goyarts and Dänicke, 2006; Dänicke et al., 2006). Immune homeostasis can also be maintained by the intestinal 
epithelial cells (IEC) when they come into contact with commensal bacteria, and the most crucial key to coexistence of commensal bacteria and IECs is the ability to segregate host cells from microorganisms. This notwithstanding, disruptions occurring in the intestinal epithelial barrier pose risk of infection and inflammatory responses (Yan et al., 2013). In broiler chickens, T-2 causes reduced feed intake and body weight gain, but also severe oral lesions and immunological dysfunction (Devegowda and Murthy, 2005). Clinical signs depend on the exposure time and on the dose of the toxin. Moreover, this toxin causes oxidative stress that alters the cell cycle and induces apoptosis in vitro and in vivo (Islam et al., 1998; Chen et al., 2008). Ghareeb et al. (2006) reported that feeding $10 \mathrm{mg}$ DON/kg to chicken altered the humoral immune response to viral vaccine, decreased the level of alanine transaminase (ALT), increased serum cholesterol concentration and the amount of circulating triglycerides. Moreover, Chen et al. (2017) verified that DON may cause a disturbance to the immune system and alter the intestinal barrier in Taiwan country chickens, and may also lead to irregularities in growth performances in a dose- and sex-dependent manner (Chen et al., 2017). For an immune response to be effective, the right mechanism, or combination of mechanisms, must be activated. However, for each species there are many diseases for which immunity does not exist. Also, under certain circumstances, these normally protective responses can result in significant tissue damage, which leads to immune-mediated diseases. The summary of the effects of DON on the gut microbiota and immune system of chicken is presented in Figure 2.

\section{References}

2006/576/EC (2006). Commission recommendation of 17th August 2006 on the presence of deoxynivalenol, zearalenone, ochratoxin A, T-2 and HT-2 and fumonisins in products intended for animal feeding. Off. J. Eur. Union L229, pp. 7-9.

A las s a ne-Kpembi I., Pue 1 O., Oswald I.P. (2015). Toxicological interactions between the mycotoxins deoxynivalenol, nivalenol and their acetylated derivatives in intestinal epithelial cells. Arch Toxicol., 89:1337-1346.

Andretta I., K i p per M., L ehnen C.R., Ha u s child L., Va le M.M., Lovat to P.A. (2011). Meta-analytical study of productive and nutritional interactions of mycotoxins in broilers. Poultry Sci., 90: 1934-1940.

Antonissen G., van Immerseel F., Pas mans F., Ducatelle R., Jans sens G.P.J., d e B a e r e S. (2015). Mycotoxins deoxynivalenol and fumonisins alter the extrinsic component of intestinal barrier in broiler chickens. J. Agric. Food Chem., 63: 10846-10855.

Aw ad W.A., Böhm J., Razzazi-Fazeli E., Hulan H.W., Zentek J. (2004). Effects of deoxynivalenol on general performance and electrophysiological properties of intestinal mucosa of broiler chickens. Poultry Sci., 83: 1964-1972.

Awad W.A., Razzazi-Fazeli E., Böhm J., Ghareeb K., Zentek J. (2006 a). Effect of addition of a probiotic microorganism to broiler diets contaminated with deoxynivalenol on performance and histological alterations of intestinal villi of broiler chickens. Poultry Sci., 85: 974-979.

Aw a d W.A., B ö h m J., R a z z a z i - F a ze li E., Z e n t e k J. (2006 b). Effects of feeding deoxynivalenol contaminated wheat on growth performance, organ weights and histological parameters of the intestine of broiler chickens. J. Anim. Nutr. Anim. Physiol., 90: 32-37.

Aw a d W.A., Hes s M., Twaruzek M., Grajews ki J., Kos icki R., Böhm J. (2011 a). The impact of the Fusarium mycotoxin deoxynivalenol on the health and performance of broiler chickens. Int. J. Mol. Sci., 12: 7996-8012. 
Aw a d W.A., Vahjen W., A s che n b a ch J.R., Z e n t e k J. (2011 b). A diet naturally contaminated with the Fusarium mycotoxin deoxynivalenol (DON) downregulates gene expression of glucose transporters in the intestine of broiler chickens. Livest. Sci., 140: 72-79.

Awad W.A., Ghareeb K., Chimidtseren S., Strasser A., Hes s M., B öh J. (2012 a). Chronic effects of deoxynivalenol on plasma cytokines and vaccine response of broiler chickens. In: Proceedings of the 34th Mykotoxin-Workshops der Ges. für Mykotoxin Forschung e.V., Braunschweig, Germany.

Aw a d W.A., Ghare eb K., Da dak A., Gille L., Staniek K., Hes s M., Böh m J. (2012 b). Genotoxic effects of deoxynivalenol in broiler chickens fed with low protein diets. Poultry Sci., 91: $550-555$.

Aw a d W.A., G har e e b K., B ö h m J., Z e n t e k J. (2013). The toxicological impacts of the Fusarium mycotoxin, deoxynivalenol, in poultry flocks with special reference to immunotoxicity. Toxins, 5: 912-925.

B a c k h e d F., L e y R.E., S o n n e n bu r g J.L., P e ter s o n D.A., Gordon J.I. (2005). Host-bacterial mutualism in the human intestine. Science, 307:1915-1920.

B e cker C., Re iter M., Pfaffl M.W., Meyer H.H.D., B a u e r J., Meyer K.H.D. (2011). Expression of immune relevant genes in pigs under the influence of low doses of deoxynivalenol (DON). Mycotoxin Res., 27: 287-293.

B j errum L., Eng berg R.M., Le s e r T.D., J en s en B.B., Finst er K., P e d e r s e n K. (2006). Microbial community composition of the ileum and cecum of broiler chickens as revealed by molecular and culture-based techniques. Poultry Sci., 85: 1151-1164.

B on d y G.S., P e s t k a J.J. (1991). Dietary exposure to the trichothecene vomitoxin (deoxynivalenol) stimulates terminal differentiation of Peyer's patch B cells to IgA secreting plasma cells. Toxicol. Appl. Pharmacol., 108: 520-530.

B o n d y G.S., P e s t k a J.J. (2000). Immunomodulation by fungal toxins. J. Toxicol. Environ. Health B, 3: 109-143.

B ou het S., Hourcade E., Lo is e a N., Fikry A., Martinez S., Roselli M., Galtier P., Mengheri E., Oswald I.P. (2004). The mycotoxin fumonisin B1 alters the proliferation and the barrier function of porcine intestinal epithelial cells. Toxicol. Sci., 77: 165-171.

B o u h e t S., O s w a ld I.P. (2005). The effects of mycotoxins, fungal food contaminants, on the intestinal epithelial cell-derived innate immune response. Vet. Immunol. Immunopathol. 108, 199-209.

Chen P., J i P., L i S.L. (2008). Effects of feeding extruded soybean, ground canola seed and whole cottonseed on ruminal fermentation, performance and milk fatty acid profile in early lactation dairy cows. Asian-Australas. J. Anim. Sci., 21: 204-213.

Ch en S.S., L i Y.H., L in M.F. (2017). Chronic exposure to the Fusarium mycotoxin deoxynivalenol: impact on performance, immune organ, and intestinal integrity of slow-growing chickens. Toxins (Basel), 9: 334.

Chen W., Li u F., Ling Z., Tong X., Xiang C. (2012). Human intestinal lumen and mucosaassociated microbiota in patients with colorectal cancer. PLoS ONE 7: e39743.

Ch en g Y.H., Ch a n g M.H., L in Y.A., W u J.F., C h e n B.J. (2004). Effects of deoxynivalenol and degradation enzyme on growth performance and immune responses in mule ducks. J. Anim. Feed Sci., 13: 275-287.

C l a e s s o n M.J., O' T o o le P.W. (2010). Evaluating the latest high-throughput molecular techniques for the exploration of microbial gut communities. Gut Microbes., 1: 277-278.

C l a e s s o n M.J., J e ffe ry I.B., C on d e S., P ow e r S.E., O ' C on nor E.M., C u s a c k S. (2011). Gut microbiota composition correlates with diet and health in the elderly. Nature, 488: 178-184

Cornick S., Tawi a h A., Chad e e K. (2015). Roles and regulation of the mucus barrier in the gut. Tissue Barriers 3: e982426.

Cortinovis C., Pizzo F., Spicer L.J., Caloni F. (2013). Fusarium mycotoxins: effects on reproductive function in domestic animals - a review. Theriogenology, 80: 557-564.

Dänicke S., U eberschär K.H., Matthes S., Halle I., Valenta H., Flachowsky G. (2002). Effect of addition of a detoxifying agent to laying hen diets containing uncontaminated or Fusarium toxin contaminated maize on performance of hens and on carryover of zearalenone. Poultry Sci., 81: 1671-1680.

Dänicke S., Matthes S., Halle I., Ueberschar K.H., Döll S., Valenta H. (2003). Ef- 
fects of graded levels of Fusarium toxin contaminated wheat and of a detoxifying agent in broiler diets on performance, nutrient digestibility and blood chemical parameters. Br. Poult. Sci., 44: $113-126$.

Dänicke S., U e bers chär K.H., Valenta H., Matthes S., M a t thäus K., H alle I. (2004). Effects of graded levels of Fusarium-toxin-contaminated wheat in Pekin duck diets on performance, health and metabolism of deoxynivalenol and zearalenone. Br. Poult. Sci., 45: 264-272.

Dänicke S., Goyarts T., Doll S., Grove N., Spolders M., Flachowsky G. (2006). Effects of the Fusarium toxin deoxynivalenol on tissue protein synthesis in pigs. Toxicol. Lett., 165: 297-311.

Dänicke S., Valent a H., U e be r s c här K.H., M a t thes S. (2007). On the interactions between Fusarium toxin-contaminated wheat and non-starch-polysaccharide hydrolysing enzymes in turkey diets on performance, health and carry-over of deoxynivalenol and zearalenone. Br. Poult. Sci., 48: 39-48.

De La Cochetiere M.F., Durand T., Lepage P., Bourreille A., Galmiche J.P., D or é J. (2005). Resilience of the dominant human fecal microbiota upon short-course antibiotic challenge. J. Clin. Microbiol., 43: 5588-5592.

Ders ja n t-Li Y., Verst e gen M.W.A., Gerrits W.J.J. (2003). The impact of low concentrations of aflatoxin, deoxynivalenol or fumonisin in diets on growing pigs and poultry. Nutr. Res. Rev., 16: 223-239.

D e s j a r d in s A.E. (2006). Mechanism of Action of Trichothecenes. In Fusarium Mycotoxins: Chemistry, Genetics and Biology; APS Press: St. Paul, MN, USA, pp. 53-54.

D evegowda G., Murthy T.N.K. (2005). Mycotoxins: their effects in poultry and some practical solutions. In: The Mycotoxin Blue Book, Diaz D.E. (Ed.). Nottingham, United Kingdom, pp. 25-56.

Dohrman A., Miyata S., Gallup M., Li J.D., Chapelin C., Coste A. (1998). Mucin gene (MUC 2 and MUC 5AC) upregulation by gram-positive and gram-negative bacteria. Biochim. Biophys. Acta, 1406: 251-259.

Eriks e n G.S., P e tt e r s s o n H. (2004). Toxicological evaluation of trichothecenes in animal feed. Anim. Feed Sci. Technol., 114: 205-239.

Es crivá L., F on t G., Manyes L. (2015). In vivo toxicity studies of Fusarium mycotoxins in the last decade: a review. Food Chem. Toxicol., 78: 185-206.

F e i n b e rg B., M c l a u g h 1 in C.S. (1989). Biochemical Mechanism of Action of Trichothecene Mycotoxins. In: Beasley V.R. (Ed.), Trichothecene Mycotoxicosis: Pathophysiologic Effects, CRC Press: Boca Raton, FL, USA, I: 27-35.

Gajęcka M., Tarasiuk M., Zielonka L., Dąbrowski M., Nicpoń J., Baranows k i M., G a ję c k i M.T. (2017). Changes in the metabolic profile and body weight of pre-pubertal gilts during prolonged monotonic exposure to low doses of zearalenone and deoxynivalenol. Toxicon, 125: 32-43.

G e Y., E z ze l R.M., Wa r r e n H.S. (2000). Localization of endotoxin in the rat intestinal epithelium. J. Infect. Dis., 182: 873-881.

Gha re e b K., Aw a d W.A., B ö h m J. (2012). Ameliorative effect of a microbial feed additive on infectious bronchitis virus antibody titer and stress index in broiler chicks fed deoxynivalenol. Poultry Sci., 91: 800-807.

Ghar e eb K., Aw ad W.A., S o od o i C., S a s gary S., Stras s e r A., B öh m J. (2013). Effects of feed contaminant deoxynivalenol on plasma cytokines and mRNA expression of immune genes in the intestine of broiler chickens. PLoS ONE 8: e71492.

Ghare eb K., Aw a d W.A., Böhm J., Zebeli Q. (2015). Impacts of the feed contaminant deoxynivalenol on the intestine of monogastric animals: poultry and swine. J. Appl. Toxicol., 35: $327-337$.

G ha r e e b K., Aw a d W. A., B ö h m J., Z e b e li Q. (2016 a). Impact of luminal and systemic endotoxin exposure on gut function, immune response and performance of chickens. World's Poult. Sci. J., 72: 367-380.

Ghare e b K., Aw a d W.A., Z e b e 1 i Q., B o h m J. (2016 b). Deoxynivalenol in chicken feed alters the vaccinal immune response and clinical biochemical serum parameters but not the intestinal and carcass characteristics. J. Anim. Physiol. Anim. Nutr., 100: 53-60. 
Girg is G.N., Shay an S., B arta J.R., B oerman s H.J., S m ith T.K. (2008). Immunomodulatory effects of feed-borne Fusarium mycotoxins in chickens infected with Coccidia. Exp. Biol. Med., 233: 1411-1420.

G ir g is G.N., B a rt a J.R., B r a s h M., S m ith T.K. (2010). Morphological changes in the intestine of broiler breeder pullets fed diets naturally contaminated with Fusarium mycotoxins with or without coccidial challenge. Avian Dis., 54: 67-73.

Gong A.D., Li H.P., Yu an Q.S., S ong X.S., Ya o W., H e W.J., Z ha ng J.B., L i a o Y.C. (2015). Antagonistic mechanism of iturin A and plipastatin A from Bacillus amyloliquefaciens s76-3 from wheat spikes against Fusarium graminearum. PLoS ONE, 10: e0116871.

G o y a r t s T., Dä n i c k e S.(2006). Bioavailability of the Fusarium toxin deoxynivalenol (DON) from naturally contaminated wheat for the pig. Toxicol. Lett., 163: 171-182.

Gratz S.W., Duncan G., Richardson A.J. (2013). The human fecal microbiota metabolizes deoxynivalenol and deoxynivalenol-3-glucoside and may be responsible for urinary deepoxy-deoxynivalenol. Appl. Environ. Microbiol., 79: 1821-1825.

Gratz S.W., Dinesh R., Yoshinari T., Holtrop G., Richardson A.J., Duncan G. (2017). Masked trichothecene and zearalenone mycotoxins withstand digestion and absorption in the upper GI tract but are efficiently hydrolyzed by human gut microbiota in vitro. Mol. Nutr. Food Res., 61: 1600680.

Grenier B., A p p le gate T.J. (2013). Modulation of intestinal functions following mycotoxin ingestion: meta-analysis of published experiments in animals. Toxins, 5: 396-430.

Gu a rn e r F. (2006). Enteric Flora in Health and Disease. Digestion, 73 (suppl. 1): 5-12.

Guarner F., M a la g e l a d a J.R. (2003).Gut flora in health and disease. Lancet., 361: 512-519.

I s l a m Z., P e st ka J.J. (2006). LPS priming potentiates and prolongs proinflammatory cytokine. response to the trichothecene deoxynivalenol in the mouse. Toxicol. Appl. Pharmacol., 211: 53-63.

I s 1 a m Z., N a ga s e M., O t a A., U e d a S., Yos hizaw a T., S a k a to N. (1998). Structure-function relationship of T-2 toxin and its metabolites in inducing thymic apoptosis in vivo in mice. Biosci. Biotechnol. Biochem., 62: 1492-1497.

I v a no v I.I., F rutos R. de L., Man e 1 N., Yos h in a ga K., R i fk in D.B., S a r to r R.B. (2008). Specific microbiota direct the differentiation of IL-17-producing T-helper cells in the mucosa of the small intestine. Cell Host Microbe, 4: 337-349.

J i a S.L., L i u X.C., H u a ng Z., L i Y., Z h a ng L.T., L u o Y.K. (2018). Effects of chitosan oligosaccharides on microbiota composition of silver carp (Hypophthalmichthys molitrix) determined by culture-dependent and independent methods during chilled storage. Int. J. Food Microbiol., 268: 81-91.

K a n or a A., M a e s D. (2009). The role of mycotoxins in pig reproduction: a review. Vet. Med. (Praha) 54: 565-576.

K 1 a s ing K.C. (2004) Interplay between diet microbes and immune defenses of the gastrointestinal tract. In: Physiological and Ecological Adaptations to Feeding in Vertebrates, Starck J.M., Wang T. (Eds). (Plymouth, Science Publishers).

K l a s in g K.C., L e s c h in s k y T.V. (1999). Functions, costs, and benefits of the immune system during development and growth. In: 22nd International Ornithological Congress, Adams N.J., Slotow R.H. (Eds). Durban, South Africa: BirdLife South Africa, pp. 2817-2835.

K o g u t M.H., A r s e n a u lt R.J. (2016). Editorial: gut health: the new paradigm in food animal production. Front. Vet. Sci., 3: 71.

Kohl K.D., De aring M.D. (2012). Experience matters: prior exposure to plant toxins enhances diversity of gut microbes in herbivores. Ecol Lett., 15: 1008-1015.

Kubena L.F., Swans on S.P., Harvey R.B., Fletcher O.J., Rowe L.D., Phillips T.D. (1985). Effects of feeding deoxynivalenol (vomitoxin)-contaminated wheat to growing chicks. Poultry Sci., 64: 1649-1655.

Kubena L.F., Edrington T.S., Harvey R.B., Phillips T.D., Sarr A.B., Rottingh a u s G.E. (1997). Individual and combined effects of fumonisin B1 present in Fusarium moniliforme culture material and diacetoxyscirpenol or ochratoxin A in turkey poults. Poultry Sci., 76: 256-264.

Lee H.J., Ryu D. (2017). Worldwide Occurrence of Mycotoxins in Cereals and Cereal-Derived 
Food Products: Public Health Perspectives of Their Co-occurrence. J. Agric. Food Chem. 65: 7034-7051.

L e v y J. (2007). Secondary glomerular disease. Medicine, 35: 497-499.

L e y R.E., P e t e r s o n D.A., G or d o n J.I. (2006). Ecological and evolutionary forces shaping microbial diversity in the human intestine. Cell, 124: 837-848.

Li Y., Wang Z., B e i er R.C., She n J., D e S met D., D e S a e ger S. (2011). T-2 toxin, a trichothecenemycotoxin: review of toxicity, metabolism, and analytical methods. J. Agric. Food Chem., 59: $3441-3453$.

Li Y.D., Verstegen M.W.A., Gerrits W.J.J. (2003). The impact of low concentrations of aflatoxin, deoxynivalenol or fumonisin in diets on growing pigs and poultry. Nutr. Res. Rev., 16: 223-239.

L i Z., Yang Z.B., Yang W.R., Wa ng S.J., J i a n g S.Z., W u Y.B. (2012). Effects of feed-borne Fusarium mycotoxins with or without yeast cell wall adsorbent on organ weight, serum biochemistry, and immunological parameters of broiler chickens. Poultry Sci., 91: 2487-2495.

L i e w W.P.P., Mohd-Redzwan S. (2018). Mycotoxin: its impact on gut health and microbiota. Front. Cell. Infect. Mi., 8: 60.

Lu c ke A., D o u pove c B., P a u ls e n P., Z e beli Q., B öh m J. (2017 a). Effects of low to moderate levels of deoxynivalenol on feed and water intake, weight gain, and slaughtering traits of broiler chickens. Mycotoxin Res., doi 10.1007/s12550-017-0284-z.

Lucke A., Metzler-Zebeli B.U., Zebeli Q., Böhm J. (2017 b). Effects of feeding graded levels of deoxynivalenol and oral administration of lipopolysaccharide on the cecal microbiota of broiler chickens. 111-21st European Society of Veterinary and Comparative Nutrition Congress; 20-23.09.2017, Cirencester, United Kingdom.

Lun A.K., Moran E.T. Jr., Young L.G., Mc Millan E.G. (1989). Absorption and elimination of an oral dose of $3 \mathrm{H}$-deoxynivalenol in colostomized and intact chickens. Bull. Environ. Contam. Toxicol., 42: 919-925.

Lun A.K., Young L.G., M o ran J.E.T., H u n te r D.B., R o d rigu e z J.P. (1986). Effects of feeding hens a high level of vomitoxin-contaminated corn on performance and tissues residues. Poultry Sci., 65: 1095-1099.

Macpherson A.J., Harris N.L. (2004). Interactions between commensal intestinal bacteria and the immune system. Nat. Rev. Immunol., 4: 478-485.

Mares ca M., Mah foud R., Garmy N., F antini J. (2002). The mycotoxin deoxynivalenol affects nutrient absorption in human intestinal epithelial cells. J. Nutr., 132: 2723-2731.

Mares c a M., F antini J. (2010). Some food-associated mycotoxins as potential risk factors in humans predisposed to chronic intestinal inflammatory diseases. Toxicon, 56: 282-294.

Martins C. (2018). Assessment of multiple mycotoxins in breakfast cereals available in the Portuguese market. Food Chem., 239: 132-140.

Mas low sk i K.M., Ma ckay C.R. (2011). Diet, gut microbiota and immune responses. Nat. Immunol., 12: 5-9.

McCormick S.P., Stanley A.M., Stover N.A., A lex and er N.J. (2011). Trichothecenes: from simple to complex mycotoxins. Toxins, 3: 802-814.

Mengheri E., Oswald I.P. (2004). The mycotoxin fumonisin B1 alters the proliferation and the barrier function of porcine intestinal epithelial cells. Toxicol. Sci., 77: 165-171.

Noverr M.C., Huffnagle G.B. (2004). Does the microbiota regulate immune responses outside the gut? Trends Microbiol., 12: 562-568.

Oakley B.B., Lille hoj H.S., Kogut M.H., Kim W.K., Ma ure r J.J., P edroso A. (2014). The chicken gastrointestinal microbiome. FEMS Microbiol. Lett., 360: 100-112.

Osselaere A., Santos R., Hautekiet V., De Backer P., Chiers K., Ducatelle R. (2013). Deoxynivalenol impairs hepatic and intestinal gene expression of selected oxidative stress, tight junction and inflammation proteins in broiler chickens, but addition of an adsorbing agent shifts the effects to the distal parts of the small intestine. PLoS ONE, 8: e69014, doi 10.1371.

O s wald I.P., Marin D.E., B ou het S., P in ton P., Taran u I., A c c en si F. (2005). Immunotoxicological risk of mycotoxins for domestic animals. Food Add. Contam., 22: 354-360.

P e s t k a J.J. (2003). Deoxynivalenol-induced IgA production and IgA nephropathy-aberrant mucosal immune response with systemic repercussions. Toxicol. Lett., 140: 287-295. 
P e s t k a J.J. (2010). Deoxynivalenol: mechanisms of action, human exposure, and toxicological relevance. Arch. Toxicol., 84: 663-679.

P e s t k a J.J., S m o lin s k i A.T. (2005). Deoxynivalenol: Toxicology and potential effects on humans. J. Toxicol. Environ. Health B, 8: 39-69.

P estk a J.J., Mormann M.A., Warner R.L. (1989). Dysregulation of IgA production and IgA nephropathy induced by the trichothecene vomitoxin. Food Chem. Toxicol., 27: 361-368.

P e s t k a J.J., Zhou H.R., Moon Y., Chung Y.J. (2004). Cellular and molecular mechanisms for immune modulation by deoxynivalenol and other trichothecenes: Unraveling a paradox. Toxicol. Lett., 153: 61-73.

P in ton P., O s w a ld I.P. (2014). Effect of deoxynivalenol and other type B trichothecenes on the intestine: a review. Toxins, 6: 1615-1643.

Pinton P., Accensi F., B eauchamp E., Cossalter A.M., Callu P., Grosjean F., Os w a ld I.P. (2008). Ingestion of deoxynivalenol (DON) contaminated feed alters the pig vaccinal immune responses. Toxicol. Lett., 177: 215-222.

P inton P., Braicu C., Nougayrede J.P., Laffitte J., Taranu I., Oswald I.P. (2010). Deoxynivalenol impairs porcine intestinal barrier function and decreases the protein expression of claudin-4 through a mitogen-activated protein kinase dependent mechanism. J. Nutr., 140: 1956-1962.

Prelusky D.B., Hamilton R.M., Trenholm H.L., Mille r J.D. (1986). Tissue distribution and excretion of radioactivity following administration of $14 \mathrm{C}$-labeled deoxynivalenol to White Leghorn hens. Fundam. Appl. Toxicol., 7: 635-645.

Reddy K.E., Le e W., Young J e ong J., Le e Y., L e e H.J., Kim M.S. (2018). Effects of deoxynivalenol- and zearalenone-contaminated feed on the gene expression profiles in the kidneys of piglets. Asian-Australas. J. Anim. Sci., 31: 138-148.

R i ch ard J.L. (2007). Some major mycotoxins and their mycotoxicoses - An overview. Int. J. Food Microb., 119: 3-10.

Robert H., Payros D., Pinton P., Théodorou V., Mercier-Bonin M., Os wald I.P. (2017). Impact of mycotoxins on the intestine: are mucus and microbiota new targets? J. Toxicol. Environ. Health B, 20: 249-275.

R ocha O., Ans ari K., D o oh an F.M. (2005). Effects of trichothecene mycotoxins on eukaryotic cells: A review. Food Add. Contam., 22: 369-378.

Romer Labs' Guide to Mycotoxins (2000). Mycotoxins - An Overview. Richard J.L. (Ed.), Anytime Publishing Services: Leicestershire, UK, 1, pp. 1-48.

R ot ter B., Prelusk y D.B., P e s t k a J.J. (1996). Toxicology of deoxynivalenol. J. Toxicol. Environ. Health, 48: 1-34.

Round J.L., Mazmanian S.K. (2009). The gut microbiota shapes intestinal immune responses during health and disease. Nat Rev Immunol., 9: 313-323.

S a d i a R., S chein M., M a c farla ne C., B offard K.D. (1990). Gut barrier function and the surgeon. Br. J. Surg., 77: 487-492.

S chat z m a y r G., S tre it E. (2013). Global occurrence of mycotoxins in the food and feed chain: facts and figures. World Mycotoxin Journal, 6: 213-222.

Sharmar R., Rooke J., Kolmogorova D., Melanson B., Mallet J.F., Matar C., S c h w a r z J., I s m a il N. (2018). Sex differences in the peripheral and central immune responses following lipopolysaccharide treatment in pubertal and adult CD-1 mice. Int. J. Dev. Neurosci., 71: 94-104.

S mirnova M.G., Guo L., Birchall J.P., Pearson J.P. (2003). LPS up-regulates mucin and cytokine mRNA expression and stimulates mucin and cytokine secretion in goblet cells. Cell. Immunol., 221: 42-49.

Stuper-Szablewska K., Szablewski T., Buszko M., Perkowski J. (2016). Changes in contents of trichothecenes during commercial grain milling. LWT-Food Sci. Technol., 69: 55-58.

S u m m e r el1 B.A., L e s l i e J.F. (2011). Fifty years of Fusarium: how could nine species have ever been enough? Fungal Divers., 50: 135-144.

Suzuki T., Iwahashi Y. (2015). Low toxicity of deoxynivalenol-3-glucoside in microbial cells. Toxins (Basel), 7: 187-200. 
Waśkiewicz A., Beszterda M., Kostecki M., Zielonka Ł., Goliński P., Gajęc k i M. (2014). Deoxynivalenol in the gastrointestinal tract of immature gilts under per os toxin application. Toxins, 6: 973-987.

W i s e M.G., S i rag u s a G.R. (2007). Quantitative analysis of the intestinal bacterial community in one to three week old commercially reared broiler chickens fed conventional or antibiotic free vegetable based diets. J. Appl. Microbiol., 102: 1138-1149.

W u Q.J., Z h o u Y.M., W u Y.N., Z hang L.L., Wang T. (2013). The effects of natural and modified clinoptilolite on intestinal barrier function and immune response to LPS in broiler chickens. Vet. Immunol. Immunopathol., 153: 70-76.

Yunus A.W., Ghare eb K.K., Tw a ruze k M., Graje w s ki J., B ö h m J. (2012). Deoxynivalenol as a contaminant of broiler feed: Effects on bird performance and response to common vaccines. Poultry Sci., 91: 844-851.

Zhang Q., Eicher S.D., Ajuw on K.M., Applegate T.J. (2017). Development of a chicken ileal explant culture model for measurement of gut inflammation induced by lipopolysaccharide. Poultry Sci., 96: 3096-3103.

Z h u X.Y., Joerger R.D. (2003). Composition of microbiota in content and mucus from cecae of broiler chickens as measured by fluorescent in situ hybridization with group specific, 16S rRNAtargeted oligonucleotide probes. Poultry Sci., 82: 1242-1249.

Received: 15 XI 2018

Accepted: 7 II 2019 